\title{
Retrospective study of post-operative care in pandemic in tertiary care centre
}

\author{
E. Rohini' ${ }^{1}$, N. R. Indu ${ }^{1 *}$, A. Shameera Banu ${ }^{1}$, P. B. Hiremath ${ }^{1}$, Reshma Hiremath ${ }^{2}$
}

\author{
${ }^{1}$ Department of Obstetrics and Gynecology, SVMCH and RC, Ariyur, Puducherry, India \\ ${ }^{2}$ IMO, ESI, Mapusa, Goa, India
}

Received: 18 December 2021

Revised: 16 January 2022

Accepted: 17 January 2022

\section{*Correspondence:}

Dr. N. R. Indu,

E-mail: roh8846@gmail.com

Copyright: () the author(s), publisher and licensee Medip Academy. This is an open-access article distributed under the terms of the Creative Commons Attribution Non-Commercial License, which permits unrestricted non-commercial use, distribution, and reproduction in any medium, provided the original work is properly cited.

\begin{abstract}
Background: COVID-19 pandemic has unfortunately changed the surgical interventions and the post-operative management worldwide. Most of the medical institutes in India had formulated their own protocols from the beginning of the pandemic in March 2020 to stop all elective surgical procedures as soon as possible. However emergencies and all types of obstetric as cases were not stopped as it was unavoidable conditions.

Methods: This retrospective observational study was done in the department of obstetrics and gynaecology, at Sri Venkateshwaraa Medical College, Ariyur, Puducherry, during the period April 2020-December 2020. Data was collected from the case sheets and operative notes and retrospective analysis was done.

Results: On analysing we have realised that LSCS rate was higher and induction for trial of labour was kept minimal. We had 3 infective morbidity in the form of wound infection and 1 patient was returned to the operation theatre for reexploration. Arranging the blood during the pandemic was also a tedious task.

Conclusions: In the present era of pandemic, where the patient load is high, we can rely on post graduate students to look after the post-operative patients through effective communication with the available consultants.
\end{abstract}

Keywords: Hysterectomy, Caesarean section, Post-operative care, Morbidity, Mortality, Laparoscopy, Wound infection

\section{INTRODUCTION}

COVID-19 pandemic has unfortunately changed the surgical interventions and the post-operative management worldwide. COVID suspected pregnant patients were managed irrespective of their COVID status during the obstetric emergencies. Gynaecological procedures were done on priority basis depending on the emergency and semi emergency as and when required. Despite the many obstetric societies which had provided guidelines to aid in selecting the cases, challenges had remained both during the current period of crisis and over the several months after the peak of the pandemic. ${ }^{1}$
The ill effects of the failure to modify the surgery schedule had been demonstrated in countries like China and Italy where the elective surgeries and non-essential clinical visits contributed significantly to the in-hospital COVID19 transmission., ${ }^{2,3}$ Having empty operating rooms and inpatient beds prior to the peak of the pandemic are an essential measure to be prepared for the large volume of critically ill patients within a short span of time. Hospitals in United States (US) and Canada had developed a similar framework -"crisis standards of care" where resources become scarce during crisis. ${ }^{4}$

Most of the medical institutes in India had formulated their own protocols from the beginning of the pandemic in 
March 2020 to stop all elective surgical procedures as soon as possible. However emergencies and all types of obstetric cases were continued as it was unavoidable.

\section{Aims and objectives}

Aims and objectives include: to audit the surgical procedures during the COVID pandemic; and to study the morbidity and mortality in post-operative patients during the COVID pandemic.

\section{METHODS}

2020 pandemic has devastated the entire humanity all over the globe. The routine policy of obstetric and gynaecological patient care was disturbed tremendously. Due to the pandemic many doctors were quarantined, some were on leave, some were infected. The strength of the working hands were reduced to less than 50\%. All elective gynaecological surgeries were cancelled till further orders. However obstetric practice and emergency gynaecological services were available in the institute. The routine care of normal obstetric and post-operative care was hampered. Rounds of all the units were taken by junior resident doctors and discussed with the consultants, decisions were taken accordingly. Patients were brought to the consultants only when essential but otherwise not routinely seen by the consultants.

The pandemic situation like this could change the postoperative outcome of the patients probably not due to the COVID pandemic itself but due to the human behaviour.

The retrospective study was conducted at SVMCH and RC from April 2020 to December 2020 to know the surgical outcome in the form of morbidity and mortality during the pandemic.

All the operated cases in the department during the study period were taken into consideration. Details of all the patients and the surgical profile were collected from the medical records department and was documented. Analysis was done based on the demographics, type of the surgery and the outcome. Patients who were COVID infected or suspected were excluded from the study.

\section{RESULTS}

This study was conducted in SVMCH and RC in Ariyur, Puducherry from the period of April 2020 to December 2020 during the peak of COVID pandemic in India. This study was conducted with the intention to know the surgical morbidity and mortality in the department of obstetrics and gynaecology during the pandemic. As the pandemic changed the medical practice like elective cases being deferred, minimal staff for the surgery, single person taking the post-operative rounds on rotation, only half of the strength of faculty working and continued emergency obstetric practice.
Table 1: Age wise distribution.

\begin{tabular}{|lll|}
\hline Age & Number & Percentage \\
\hline$<30$ & 121 & 60.5 \\
\hline $\mathbf{3 1 - 4 0}$ & 48 & 24 \\
\hline $\mathbf{4 1 - 5 0}$ & 21 & 10.5 \\
\hline$>\mathbf{5 0}$ & 10 & 5 \\
\hline
\end{tabular}

Our study included 200 post-operative cases out of which $121(60.5 \%)$ were less than 30 years of age, $48(24 \%)$ patients were between 31-40 years of age and only $10(5 \%)$ patients were around 50 years of age. This strength was probably due to uncompromised obstetric practice and elderly patients were reluctant to approach hospitals due to the fear of COVID and their comorbidities (Table 1).

We have performed around $132(66 \%)$ caesarean sections with or without sterilisation due to the various indications, the most common indication being previous LSCS which was an indication in 32 patients followed by pre eclampsia and fetal distress. The least indication was malpresentation and malposition like DTA. On analysing we have realised that LSCS rate was higher and induction for trial of labour was kept minimal. There were 68 gynaecological surgeries which were performed either due to severe anemia as a result of AUB or due to acute complications or on request. Among the gynaecological surgeries 29 cases were hysterectomies out of which 2 were laparoscopic assisted vaginal hysterectomies which were performed during the later stages of pandemic as we had cancelled laparoscopy for few months during the peak. Followed by vaginal hysterectomy in 5 cases. Rest were all minor cases (Table 2).

This study was conducted to know the surgical morbidity and mortality when the responsibility of postoperative management of cases were left to the post graduate students during the pandemic. When the audit for the purpose of the research of post-operative cases was done, we realised that fortunately we did not have any mortality. However we had 3 infective morbidity in the form of wound infection and one patient was returned to the operation theatre for re-exploration. The patient was a case of post-operative vaginal hysterectomy followed by pelvic abscess for which laparotomy was done. There was bowel injury during the laparotomy which was repaired. This patient was monitored by the post graduates and they had failed to recognise the signs of fecal peritonitis due to the opening up of the repaired bowel injury site. Subsequently the patient was managed by the team with exploratory laparotomy and was discharged in a good condition. On a retrospective analysis, we realised that patient was an uncontrolled diabetic and on oral steroid supplementation for hypopituitarism following a surgery for pituitary adenoma. Around 18 patients received blood transfusion as they were anemic or had lost blood during the surgery. Arranging the blood during the pandemic was also a tedious task but was made possible with the help of blood bank officer in the need of emergencies (Tables 3 and 4). 
Table 2: Indications for the surgeries.

\begin{tabular}{|c|c|c|c|c|}
\hline Type of surgery & \multicolumn{2}{|l|}{ Indication } & Number & Percentage \\
\hline \multirow{13}{*}{ LSCS \pm sterilisation } & Severe oligohydramnios & 15 & \multirow{13}{*}{132} & \multirow{13}{*}{ erime } \\
\hline & CPD & 12 & & \\
\hline & Uncontrolled HTN & 18 & & \\
\hline & Failed induction & 12 & & \\
\hline & Previous LSCS & 32 & & \\
\hline & Breech & 6 & & \\
\hline & Fetal distress & 18 & & \\
\hline & Placenta previa & 4 & & \\
\hline & NPOL & 6 & & \\
\hline & Previous CPT & 1 & & \\
\hline & IUGR & 5 & & \\
\hline & DTA & 1 & & \\
\hline & Malpresentation & 2 & & \\
\hline $\mathbf{I V H}$ & Adenomyosis & 1 & 2 & 1 \\
\hline LAVH & AUB-O & 1 & 2 & 1 \\
\hline & AUB-O & 8 & & \\
\hline Abdominal hysterectomy & AUB-L & 9 & 22 & 11 \\
\hline & AUB-A & 5 & & \\
\hline Vaginal hysterectomy & Third degree UV prolapse & & 5 & 2.5 \\
\hline Puerperal sterilisation & Contraception & & 3 & 1.5 \\
\hline Tubal recanalisation & s/p tubal ligation & & 3 & 1.5 \\
\hline Ovarian cyst excision & Ovarian cyst & & 3 & 1.5 \\
\hline Marsupulisation & Bartholins cyst & & 1 & 0.5 \\
\hline Laparoscopic cyst excision & Ovarian cyst & & 1 & 0.5 \\
\hline Diagnostic hysterolaparoscopy & Primary infertility & & 1 & 0.5 \\
\hline Abdominal sacrocolpopexy & Vault prolapse & & 1 & 0.5 \\
\hline Myomectomy & Fibroid uterus & & 4 & 2 \\
\hline Dilatation and evacuation & Incomplete abortion & & 7 & 3.5 \\
\hline Fractional curettage & AUB & & 6 & 3 \\
\hline Dilation and curettage with LNG IUS insertion & AUB-O & & 4 & 2 \\
\hline Missing copper T removal & Missing $\mathrm{Cu} \mathrm{T}$ & & 2 & 1 \\
\hline Perineal tear repair & Perineal tear & & 1 & 0.5 \\
\hline Hysterotomy & Anomalous fetus with pres & LSCS & 1 & 0.5 \\
\hline
\end{tabular}

Table 3: Co-morbidities.

\begin{tabular}{|lll|}
\hline Co-morbidity & Number & Percentage \\
\hline Gestational diabetes mellitus & 8 & 4 \\
\hline Diabetes mellitus & 6 & 3 \\
\hline Hypertension & 5 & 2.5 \\
\hline Bronchial asthma & 1 & 0.5 \\
\hline Thyroid disorder & 8 & 4 \\
\hline Anemia & 15 & 7.5 \\
\hline Ca breast & 1 & 0.5 \\
\hline PIH & 19 & 9.5 \\
\hline
\end{tabular}

Table 4: Post-operative morbidity and mortality.

\begin{tabular}{|llllllll} 
Type of surgery & Number & Mortality & $\begin{array}{l}\text { Blood } \\
\text { transfusion }\end{array}$ & $\begin{array}{l}\text { Return to } \\
\text { operating } \\
\text { room }\end{array}$ & $\begin{array}{l}\text { Wound } \\
\text { morbidity }\end{array}$ & $\begin{array}{l}\text { Respiratory } \\
\text { morbidity }\end{array}$ & $\begin{array}{l}\text { VTE } \\
\text { LSCS }\end{array}$ \\
\hline LSCS with sterilisation & 51 & 0 & 4 & 0 & 0 & 0 & 0 \\
\hline
\end{tabular}




\begin{tabular}{|c|c|c|c|c|c|c|c|}
\hline Type of surgery & Number & Mortality & $\begin{array}{l}\text { Blood } \\
\text { transfusion }\end{array}$ & $\begin{array}{l}\text { Return to } \\
\text { operating } \\
\text { room }\end{array}$ & $\begin{array}{l}\text { Wound } \\
\text { morbidity }\end{array}$ & $\begin{array}{l}\text { Respiratory } \\
\text { morbidity }\end{array}$ & VTE \\
\hline LAVH & 2 & & 0 & 0 & 0 & 0 & 0 \\
\hline Abdominal hysterectomy & 23 & 0 & 10 & 0 & 1 & 0 & 0 \\
\hline Vaginal hysterectomy & 5 & 0 & 0 & 1 & 0 & 0 & 0 \\
\hline Puerperal sterilisation & 3 & 0 & 0 & 0 & 0 & 0 & 0 \\
\hline Tubal recanalisation & 3 & 0 & 0 & 0 & 0 & 0 & 0 \\
\hline Ovarian cyst excision & 3 & 0 & 0 & 0 & 0 & 0 & 0 \\
\hline Marsupulisation & 1 & 0 & 0 & 0 & 0 & 0 & 0 \\
\hline $\begin{array}{l}\text { Laparoscopic cyst } \\
\text { excision }\end{array}$ & 1 & 0 & 0 & 0 & 0 & 0 & 0 \\
\hline $\begin{array}{l}\text { Diagnostic } \\
\text { hysterolaparoscopy }\end{array}$ & 1 & & 0 & & 0 & 0 & 0 \\
\hline $\begin{array}{l}\text { Abdominal } \\
\text { sacrocolpopexy }\end{array}$ & 1 & 0 & 0 & 0 & 0 & 0 & 0 \\
\hline Myomectomy & 4 & 0 & 0 & 0 & 1 & 0 & 0 \\
\hline $\begin{array}{l}\text { Dilatation and } \\
\text { evacuation }\end{array}$ & 7 & 0 & 1 & 0 & 0 & 0 & 0 \\
\hline Fractional curettage & 6 & 0 & 0 & 0 & 0 & 0 & 0 \\
\hline $\begin{array}{l}\text { Dilation and curettage } \\
\text { with LNG IUS insertion }\end{array}$ & 4 & 0 & 1 & 0 & 0 & 0 & 0 \\
\hline $\begin{array}{l}\text { Missing copper T } \\
\text { removal }\end{array}$ & 2 & 0 & 0 & 0 & 0 & 0 & 0 \\
\hline Perineal tear repair & 1 & 0 & 0 & 0 & 0 & 0 & 0 \\
\hline Hysterotomy & 1 & 0 & 0 & 0 & 0 & 0 & 0 \\
\hline
\end{tabular}

\section{DISCUSSION}

The COVID-19 pandemic has created a freakish burden on the healthcare individuals all over the world. Multiple efforts to reduce the transmission has been attempted like social distancing, closure of public spaces, and quarantines. The measures are required to ensure both patient care and staff safety. Amongst this unraveling pandemic, diseases require treatment on triage basis. Patients will require post-op care, emergency procedures, and surgical evaluations for time-dependent new diagnoses. The triage strategy shouldn't only consider the blanket policy but on the data and expert opinion from clinicians and site specific understanding of issues in play.

During the pandemic all surgical specialties had to adapt to the various changes. They had to limit their surgical practices and rationalize the surgeries which are performed. Selection of patients for urgent surgery during the pandemic is crucial to ensure patients have postoperative reserves to combat any possibility of later being infected with COVID-19.

Different strategies were used at various levels, one of them was using personal protective equipment (PPE) kit for any in-patient surgical consult, these PPE could be used conservatively by utilizing providers who have already donned PPE in the process of caring for COVID suspected patients to perform the physical exam, multiple consultations at once, minimizing viral exposure to the
COVID provider and reducing the risk of transmission to other staff and patients.

Telemedicine offers a variety of modalities easily accessible by patients and surgeons in the pre and postoperative periods. ${ }^{5,6}$ Video chats and images taken on a smartphone are effective for follow-ups, which could detect post-operative complications and even saves patient's time. ${ }^{7}$ A study was done in 2017 where mobile phone images for early detection of post-operative complications following appendicectomy (laparoscopic or open) and found a $100 \%$ sensitivity, $91.6 \%$ specificity, and a negative predictive value of $100 \% .^{8}$ These affirmative results included patients undergoing complex oncologic surgeries. ${ }^{9,10}$

Surgeons from different specialties had been guided to consider non-surgical treatment where safe and possible to avoid unnecessary hospital admissions and to avoid spread of infection and follow up visits were limited by accessing telephone and video whenever feasible. ${ }^{11}$

Even before the pandemic declaration by the World Health Organization (WHO), it was understood that postponing elective activities was a crucial step, in order to preserve patients' safety and to limit the viral spread. This step could increase the resources for COVID-19 patients, clearing ward and intensive care unit (ICU) beds and also avoids unnecessary patient traffic in the hospital and reduces the risk of cross-infection between elective patients, hospital visitors and COVID-19 patients, 
preventing spread of infection from the hospital to the community. ${ }^{12,13}$

Postponing surgical treatment was like double edged sword if on one hand, postponing elective procedures was necessary, on the other, every delay in treatment could lead to adverse outcomes. It becomes the responsibility of the clinicians to assess the risk of proceeding and delaying surgery considering that a possible time of 6-7 weeks could be necessary to see a decrease in peak of COVID-19 prevalence. $^{14}$

All through the COVID-19 pandemic, professional societies and national organizations in the United States have been offering guidance related to elective procedures, initially calling for their cancellation and later issuing guidance for their resumption. ${ }^{15}$ Centers for Disease Control and Prevention (CDC) has offered guidance on effective use of PPE on the basis of anticipated inventory and demand. ${ }^{16}$ The CDC also offers strong guidance to the population about ways to protect against COVID-19 and to health care providers about ways to safely care for patients who do not have Covid-19 and prevent the further spread of the disease. ${ }^{17,18}$ These guidelines support the decision to defer elective surgeries. Many millions of elective surgeries were cancelled during the first wave of the pandemic this had helped in redistribution of staff and resources to provide optimum care. ${ }^{19}$

Our idea of conducting this retrospective study is to find out the reliability of post graduate student's efficiency in taking care of the post-operative patients. Ultimately this study helped us to audit the indications of the surgeries, the post-operative complications and to test the efficiency and communication skills of the post graduate students in avoiding the post-operative morbidity.

\section{Limitations}

The number of surgeries done were fewer and due to the triage only emergency cases were focussed upon.

\section{CONCLUSION}

In the present era of pandemic, where the patient load is high, we can rely on post graduate students to look after the post-operative patients through effective communication with the available consultants.

\section{Funding: No funding sources}

Conflict of interest: None declared

Ethical approval: The study was approved by the Institutional Ethics Committee

\section{REFERENCES}

1. Brindle EM, Doherty G, Lillemore K, Gawande A. Approaching surgical triage during the COVID-19 Pandemic. Ann Surg. 2020;272(2):40-2.
2. Wu Z, McGoogan JM. Characteristics of and important lessons from the coronavirus disease 2019 (COVID-19) outbreak in China: summary of a report of 72314 cases from the Chinese Center for Disease Control and Prevention. JAMA. 2020;323(13):123942.

3. Rosenbaum L. Facing COVID-19 in Italy-Ethics, Logistics, and Therapeutics on the Epidemic's Front Line. N Engl J Med. 2020;382(20):1873-5.

4. Members of Harvard Medical School Center for Bioethics. A message to the public from Mass. doctors, nurses, and ethicists about the coronavirus. The Boston Globe. 2020.

5. Asiri A, AlBishi S, AlMadani W, ElMetwally A, Househ M. The use of telemedicine in surgical care: a systematic review. Acta Inf Med. 2018;26(3):201-6.

6. Gunter RL, Chouinard S, Fernandes-Taylor S, et al. Current use of telemedicine for post-discharge surgical care: a systematic review. J Am Coll Surg. 2016;222(5):915-27.

7. Asiri A, AlBishi S, AlMadani W, ElMetwally A, Househ M. The use of telemedicine in surgical care: a systematic review. Acta Inf Med. 2018;26(3):201-6.

8. Schroeder C. Pilot study of telemedicine for the initial evaluation of general surgery patients in the clinic and hospitalized settings. Surgery Open Science. 2019;1(2):97-9.

9. Gunter RL, Chouinard S, Fernandes-Taylor S, et al. Current use of telemedicine for post-discharge surgical care: a systematic review. J Am Coll Surg. 2016;222(5):915-27.

10. Cerfolio RJ, Ferrari-Light D, Shah S. Telemedicine in thoracic surgery. J Vis Surg. 2019;5.

11. Al-Jabir A, Kerwan A, Nicola M, et al. Impact of the Coronavirus (COVID-19) pandemic on surgical practice - Part 2 (surgical prioritisation). Int J Surg. 2020;79:233-48.

12. Brindle M, Ariadne MPH, Health B, Th H. Managing COVID-19 in Surgical Systems. Ann Surg. 2020;272(1):1-2.

13. COVID-surg Collaborative, Global Guidance for Surgical Care during the COVID-19 Pandemic. BJS. 2020;107(9):1097-103.

14. American College of Surgeons. COVID-19: Guidance for Triage of Non-emergent Surgical Procedures. 2020. Available at: https://www.facs.org/covid19/clinical-guidance/triage. Accessed on 21 October 2021.

15. American College of Surgeons, American Society of Anesthesiologists, Association of perioperative Registered Nurses, American Hospital Association. Joint statement: roadmap for resuming elective surgery after COVID-19 pandemic. 2020. Available at: https://www.asahq.org/about-asa/newsroom/ news-releases/2020/04/joint-statement-on-electivesurgery-after-covid-19-pandemic. Accessed on 21 October 2021.

16. Centers for Disease Control and Prevention. Optimizing personal protective equipment (PPE) supplies. 2020. Available at: https://www. 
cdc.gov/coronavirus/2019-ncov/hcp/ppe-

strategy/index.html. Accessed on 21 October 2021.

17. Centers for Disease Control and Prevention. Your health. 2020. Available at: https://www.cdc.gov/ mmwr/volumes/69/wr/mm6930e1.htm. Accessed on 21 October 2021.

18. Centers for Disease Control and Prevention. Framework for healthcare systems providing nonCOVID-19 clinical care during the COVID-19 pandemic. 2020. Available at: https://www.cdc.gov/ coronavirus/2019-ncov/hcp/facility-planningoperations.html. Accessed on 21 October 2021.
19. COVID Surg Collaborative. Mortality and pulmonary complications in patients undergoing surgery with perioperative SARS-CoV2 infection: an international cohort study. Lancet. 2020;396:27-38.

Cite this article as: Rohini E, Indu NR, Banu AS, Hiremath PB, Hiremath R. Retrospective study of post-operative care in pandemic in tertiary care centre. Int J Reprod Contracept Obstet Gynecol 2022;11:537-42. 